\title{
The measurement of workplace incivility in Indonesia: evidence and construct validity
}

This article was published in the following Dove Press journal:

Psychology Research and Behavior Management

\author{
Seger Handoyo \\ Samian \\ Dewi Syarifah \\ Fendy Suhariadi \\ Department of Industrial and \\ Organizational Psychology, Faculty \\ of Psychology, Airlangga University, \\ Surabaya, Indonesia
}

Correspondence: Seger Handoyo Department of Industrial and Organizational Psychology, Faculty of Psychology, Airlangga University, Airlangga Street 4-6, Surabaya 60286, Indonesia

Tel +62315032770

Fax +62315025910

Email seger.handoyo@psikologi.unair.ac.id
Introduction: A large body of research in workplace incivility has largely been conducted in the West, while in Asia, it is still relatively limited despite its close relationship to local cultural norms. The purpose of this study was to explore workplace incivility experienced by employees in Indonesia and develop a workplace incivility scale based on the behaviors identified.

Methods: This research was divided into two studies. The participants in the first study were 217 employees asked to answer questions on whether they had experienced or had seen their co-workers experiencing incivility from co-workers or supervisor. The second study was the development of a workplace incivility scale based on the findings of the first study. The scale developed was tested on 561 participants in the second study. The participants were representatives of the various regions in Indonesia.

Results: Most participants (88\%) reported that they have experienced incivility by their coworker and/or their supervisor. The study found five factors of incivility behavior: personal affairs' intervention, abandonment, unfriendly communication, inconsiderate behavior, and privacy invasion. We found a set of behaviors that are similar to the original construct of workplace incivility; yet another distinctive behavior also emerged, which we identify as a unique, culturally influenced workplace incivility.

Conclusion: Therefore, research of workplace incivility should take the specific behavior in each culture into account. Construct validity of workplace incivility scale that we developed in this study is satisfying, although further comprehensive validity testing might be required.

Keywords: mistreatment, worker, incivility scale, validity, reliability, culture, unethical behavior

\section{Introduction}

Incivility in workplace is increasingly prevalent in various contexts of organizations, especially in the last decade. Three out of four respondents in a national survey in the USA stated that incivility is getting worse. ${ }^{1}$ It has been estimated that $98 \%$ of workers experience incivility, with $50 \%$ experiencing such conduct at least weekly. ${ }^{2}$ The monetary cost of experiencing incivility is estimated at $\$ 14,000$ per employee annually, due to project delays and cognitive distraction from work. ${ }^{3}$ Individuals who experience incivility may also experience psychological distress, job dissatisfaction, withdrawal from work, and career salience. ${ }^{3}$ Pearson and Porath ${ }^{4}$ found that employees who face uncivil behavior in the workplace would be deliberately reluctant to work hard, and therefore, they would become less effective and potentially disrupt the performance of the whole team/unit. Meanwhile, Lim et $\mathrm{al}^{5}$ found a significant relationship between incivility and health, well-being, and desire to resign. The adverse effects of incivility are not only on the affected individual, but also on the group or work unit, as well 
as the overall organization, as these would get impacted from low-quality job performance and satisfaction, because workplace incivility contains the Spiral Effect. ${ }^{6-8}$ Individuals who experience uncivil behavior tend to conduct a retaliatory action to the offender, and this could transform into a violent and aggressive behavior.

Andersson and Pearson ${ }^{8}$ defined incivility as low-intensity deviant acts, such as rude and discourteous verbal and nonverbal behaviors directed to co-workers with ambiguous intent to harm the target. The behaviors are often rude and unkind, not only limited to verbal behaviors, but also include nonverbal behaviors such as ignoring, disregarding, and harassing. ${ }^{5}$ Incivility differs from other behaviors under interpersonal mistreatment behaviors category, such as abusive supervision and bullying. Interpersonal mistreatment refers to behaviors such as verbal aggression (eg, swearing), disrespect (eg, interruption, public humiliation), and isolation (eg, from important work activities). ${ }^{9}$ Incivility, abusive supervision, and bullying have similar characteristics, which include aggression, disrespect for others, and isolation of others, but each of them has different intensity and frequency. ${ }^{10-12}$

In comparison with other behavioral mistreatments, incivility is the mildest form. ${ }^{13}$ Nevertheless, the research results have shown the great impact of incivility on individuals, groups, and organizations. ${ }^{3,4,6,14}$ Although the impact is quite extensive and the incidence is increasing, research on incivility in Asia has not received considerable academic attention, thus the research on it is still very rare. ${ }^{15,16}$ Research of workplace incivility in Asia, including Indonesia, is crucial for testing the sociocultural perspective of workplace incivility in Asia. ${ }^{17}$

Kane and Montgomery ${ }^{18}$ described incivility as treating other individuals in discourteous, rude, and impatient manner, or otherwise showing a lack of respect or consideration for another's dignity. What behaviors the victim feels as rude, abusive, or disrespectful can be different in various cultures. For example, handing something to another person with the left hand will be judged as impolite and insulting by the Indonesian people, but is generally not felt so by Westerners. This clearly shows that incivility is closely tied to local cultural norms. Montgomery et $\mathrm{al}^{19}$ suggested that differences in shared norms of respect may lead to different thresholds of tolerance toward workplace incivility.

Indonesia has a unique culture and consists of diverse ethnic groups. The local characters as manifestation of indigenous values should be salient for the behaviors of Indonesians. Therefore, it is necessary to conduct a specific study of Indonesians' incivility behavior to understand the pattern of incivility issues in Indonesia.

The majority of incivility studies used the Workplace Incivility Scale (WIS) ${ }^{20}$ and other scales developed in Western countries. The first WIS contained 7 items, ${ }^{3}$ but in 2013, new items were added, bringing the total to 10 items. ${ }^{21}$ Some studies used the Uncivil Workplace Behavior Questionnaire (UWBQ) from Martin and Hine. ${ }^{22}$ Some other studies employed the Modified Incivility Scale, which is a combination of UWBQ and WIS, ${ }^{22}$ and the Multidimensional Incivility Scale from Burnfield, Clark, Montgomery et al. ${ }^{23} \mathrm{~A}$ few other studies have also developed more specific measuring tools, such as the Nursing Incivility Scale, ${ }^{24}$ specifically used for nursing work, and the Incivility from Customer to Employee Scale, ${ }^{25}$ specifically used for incivility from consumers to employees. Tsuno et al's ${ }^{16}$ research in Japan applied the Modified Workplace Incivility Scale, which was developed in Canada. To date, we have not found any scale developed in Asian countries, not to mention Indonesia.

Indonesia has cultural norms associated with incivility. These cultural norms are contained in the second norm of Pancasila, which is a just and civilized humanity. The norms embodied in the second norm are universal and unique in that they recognize equality of dignity, equality of rights, and the fundamental obligations of every human being to develop mutual love for each other, mutual respect and tolerance, compassionate attitudes against others, and to uphold the values of humanity. The value-based cultural norms of Pancasila provide a particular view of what is meant by incivility. Lim and $\mathrm{Lee}^{26}$ stated that the conceptualization and operational definition of workplace incivility are typical of a particular culture. Even though research on workplace incivility in Asia has been very little, it is highly possible that incivility can be culturally influenced; therefore, we investigated workplace incivility specifically that fits to the Indonesian context. This suggestion is in line with that of Ghosh, ${ }^{17}$ which states that incivility can vary across countries. On that basis, it is important to develop a WIS in Indonesia. Prior to conducting the research, we obtained ethical clearance from the Research Ethics Committee, Faculty of Psychology, Airlangga University.

\section{Study I}

Study 1 aimed to gather data on uncivil behaviors in the workplace that usually occur in the Indonesian workplace context, which were subsequently used to develop a WIS. The method we used to obtain data was the structured interview. 


\section{Subjects}

Participation in this study was voluntary. The criterion for selecting participants was individuals who have worked for at least 2 years. They could vary from being operational workers to being in top management, either in private companies or in government agencies. In the beginning of the study, all participants provided a verbal consent statement of willingness to answer some questions related to incivility behavior. The provision of verbal consent was approved by the Research Ethics Committee, Faculty of Psychology, Airlangga University.

The participants were 217 white collar employees (120 women and $97 \mathrm{men}$ ) with the following characteristics: the youngest was 20 years of age $\left(\mathrm{M}_{\text {age }}=32.81, \mathrm{SD}=11.04\right.$, $\mathrm{Max}=58$ ), the lowest education level was senior high school, the minimum working period was 2 years $\left(\mathrm{M}_{\text {working time }}=7.20\right.$, $\mathrm{SD}=7.59$, Max=36), having at least two co-workers $\left(\mathrm{M}_{\text {co-worker }}=18.23, \mathrm{SD}=41.60, \mathrm{Max}=500\right)$, and having a direct supervisor. Most participants reported that they became a victim of incivility, either from co-workers (ever=190, never=27) or from their supervisors (ever=192, never=25).

\section{Methods and results}

The participants who served as the subjects of this study were informed in advance of what is meant by uncivil behaviors using a language easily understood by them. Workplace incivility refers to behaviors that do not indicate gentleness and kindness, courtesy, and good manners in working relationships. Another information provided was that incivility differs from other mistreatment behaviors such as bullying and aggression in that incivility is done with no intention to harm others and is based on an ambiguous intention.

Subsequently, the participants were asked the following question: "Have you ever been exposed to uncivil behaviors by your co-worker(s) within the last 12 months?," for which they should answer "yes" or "no". When they answered "yes", they were then asked to answer how often such behaviors were experienced during the past year. The participants were given six options: almost every day, at least once a week, at least once every 2 weeks, at least once every 3 weeks, at least once a month, and very rarely. Afterward, the participants were asked to answer the next question, "What kind of words, treatments, and actions have you experienced (or have you heard or seen experienced by your colleagues) that you felt as uncivil behaviors committed by your superior/leader to his/her subordinates and those which happened among coworkers?" The participants were asked to explain in detail by asking the context or situation, the individuals involved in the situation, and what happened.

The data obtained from the interviews were analyzed using thematic analysis, that is, by organizing data into themes based on the behavioral similarity. ${ }^{27}$ The researchers selected particular behaviors that were identified as uncivil and expelled other themes. The selection process was carried out by four researchers by comparing each behavior with the preset criteria. Several criteria which were found included:

- It broke the norms of mutual respect.

- It may or may not have been intended to harm the target.

- It was not physically threatening the target.

- It occurred among co-workers in the organization.

- It was beyond the organizational hierarchy which did not necessarily happen between superiors and subordinates, but they could happen between co-workers at the same level.

The following behaviors, as they do not imply a violation of the norms of mutual respect, were excluded from the list of uncivil behaviors: "leaving the work during working hours", "failing to perform the work one is responsible for", and "failing to support and contribute to the completion of a work". This selection process resulted in 85 uncivil behaviors from co-workers and 58 uncivil behaviors from superiors.

The participants were also asked to answer the following questions: "Have you ever been exposed to uncivil behaviors from your co-worker(s)?" and "Have you ever been exposed to uncivil behaviors from your superior(s)?" When the participants answered yes, they subsequently should answer the next question, "How often have you experienced incivil behavior(s) in the past year?" They were given with six options to answer this particular question: almost every day, at least once a week, at least once every 2 weeks, at least once every 3 weeks, at least once a month, ever but very rarely. The results are shown in Table 1.

\section{Discussion}

The results of study 1 given above show that there are behaviors which are generally considered as incivility in many countries, but there are also uncivil behaviors typical to a particular context, which in this study was the Indonesian context. Such typical uncivil behaviors are influenced by what an individual perceives as a violation of the norms of mutual respect. The examples of such typical uncivil behavior are "arbitrarily giving the commands to the subordinates" and "giving orders to do something that is not written in job description, including personal matters of supervisor". These 
Table I The incidence of incivil behaviors in the workplace

\begin{tabular}{lll}
\hline Frequency & $\begin{array}{l}\text { Number of } \\
\text { participants } \\
\text { experiencing } \\
\text { incivil } \\
\text { behaviors from } \\
\text { co-workers (\%) }\end{array}$ & $\begin{array}{l}\text { Number of } \\
\text { participants } \\
\text { experiencing } \\
\text { incivil } \\
\text { behaviors from } \\
\text { superiors (\%) }\end{array}$ \\
\hline $\begin{array}{l}\text { Never } \\
\text { Ever Almost every day }\end{array}$ & $\begin{array}{l}27(12.44) \\
\text { At least once a week }\end{array}$ & $25(11.52)$ \\
At least once every & $8(30.55)$ & $60(27.65)$ \\
2 weeks & $22(10.14)$ \\
At least once every & $31(14.29)$ & $7(3.23)$ \\
3 weeks & $43(19.82)$ \\
At least once a month & II (5.07) & $16(7.37)$ \\
Experienced very & $33(15.21)$ & $44(20.28)$ \\
rarely & & \\
\hline
\end{tabular}

results provide support for the statement of Montgomery et $\mathrm{al}^{19}$ that an assessment of respectful or disrespectful behaviors relates to the norms of respect for others and politeness and they may differ between countries. Therefore, WIS items would be better if the scale contains uncivil behaviors, which are both common in many countries and are typical of specific countries. This will provide a complete sample of behaviors with the use of a larger number of items, which, in turn, will improve the validity and reliability of the measurement. ${ }^{28}$

This study has confirmed the findings of Porath et $\mathrm{al}^{6}$ that $50 \%$ of the subjects experienced uncivil behavior at least once a week. This study found similar results, in which $49.31 \%$ of the subjects stated that they experienced incivil treatment(s) at least once a week from their co-worker(s) and 37.79\% experienced incivil treatment(s) from their superior(s). This research data also showed that only a few employees (about $12 \%$ ) have never experienced uncivil behaviors, either from their co-workers or their superiors. This indicates that workplace incivility is an important issue facing companies today.

\section{Study 2}

Study 2 was aimed to develop a WIS and also to test the reliability and validity of the scale, whose items include general and Indonesian-specific behaviors. This study used the results of study 1 , particularly in relation to uncivil behaviors used as items on the scale.

Participation in this study was voluntary. Prior to participating in the study, participants were given information about the study. They were asked to provide a willingness to participate through the button before proceeding to the questionnaires. They were informed that by pressing the "start" button, the participant agreed and was willing to participate in this research. The participants were 561 white collar employees (301 women and 260 men). They were representatives of various regions in Indonesia, as they came from workplaces located in 26 out of a total 34 provinces in Indonesia. Most of the participants worked in private companies (58.47\%) and government agencies $(31.55 \%)$, while the others worked in state-owned or local government-owned companies $(9.8 \%)$ and some others worked in cooperatives $(0.18 \%)$. The participants' age ranged from 19 to 71 years $\left(\mathrm{M}_{\text {age }}=35.35, \mathrm{SD}=9.46\right)$. Most of the participants had an undergraduate degree (52.94\%) or a master's degree $(34.76 \%)$ of education, while the others had high school (4.46\%), diploma (3.39\%), or doctorate $(4.46 \%)$ degree of education. The work areas of the companies where the participants worked were as follows: education $(27.27 \%)$, services $(44.74 \%)$, manufacture $(10.52 \%)$, trade $(7.84 \%)$, public services $(8.20 \%)$, media $(0.36 \%)$, and agriculture/plantation $(1.07 \%)$. Most participants worked in staff positions $(61.50 \%)$ either as functional staff or as operational staff, while the others were in the positions of supervisor $(13.90 \%)$, manager $(20.32 \%)$, or director $(4.28 \%)$.

\section{Methods and results}

The researchers applied 85 uncivil behaviors committed by co-workers and 58 uncivil behaviors committed by superiors identified in Study 1 to construct a WIS, and these identified behaviors were transformed into scale items. The first process was to list the uncivil behaviors committed by co-workers and superiors. Two key findings were obtained from this process: first, there are certain incivil behaviors by both co-workers and superiors and second, there are some behaviors that are exclusively committed by co-workers or superiors only. All behaviors that fell into the second category were selected as indicators for measuring workplace incivility. Subsequently, we constructed items that emphasized incivility committed by both co-workers and superiors, and it resulted in 45 items.

The researchers then submitted the 45 items for the expert review. Twelve psychology lecturers from the Faculty of Psychology Airlangga University acted as reviewers, and they evaluated the content of the first version of incivility scale. The expert board assessed relevance, clarity, and redundancy of all items in the scale. Relevance was assessed by examining whether the items were consistent with the definition and characteristics of workplace uncivil behavior. The experts provided discrete judgments over the 
individual items: relevant or irrelevant. Clarity was assessed by examining whether the items were clear in conveying the meaning, so that they would be easily understood by the respondents who would later use the scale. In this particular aspect, the experts were asked to provide discrete judgments over the individual items: clear or unclear. If they judged a particular item as unclear, they would suggest how to repair it. Redundancy was assessed by examining whether an item is a repetition of another item. The experts were asked to give yes or no answer for each item. If the experts gave a yes answer, which meant the item was redundant with another item, then they were asked to show the other item with which it becomes redundant.

The results of the 12 experts' assessments were analyzed to determine items' quality, whether they were valid in terms of content, because they were consistent to the construct; whether they were expressed in clear, unambiguous language; and whether they represented uncivil behaviors. Therefore, the analysis was performed by eliminating items which were considered irrelevant, choosing one of the redundant items, and refining the wordings of those which were considered unclear, according to reviewers' suggestions. After performing such an analysis, we obtained 36 items as the second version of the scale. The next process was to empirically test the scale by testing it for Indonesian employees. A total of 561 employees participated in this study. We conducted Internet surveys where the participants were required to fill questionnaires. The subjects were asked to respond the items based on their real experience using a five-point scale ranging from never, once or twice, sometimes, often, and very often.

Exploratory factor analysis and confirmatory factor analysis were performed to determine whether the incivility construct was unidimensional as suggested by Cortina et $\mathrm{al}^{7}$ or multidimensional as suggested by Martin and Hine. ${ }^{22}$ The result of exploratory factor analysis with rotation method direct oblimin $\Delta=0$ obtained a KaiserMeyer-Olkin of 0.961 , sig $=0.000$, and six factors were formed with an eigenvalue of $>1$ and a cumulative variant of $57.104 \%$, which could be explained by the factors formed. Furthermore, the items distributed on the six formed factors were selected based on a loading factor $\geq 0.4 .{ }^{27}$ After the selection of items that have loading factors of $\geq 0.4$, a factor that contained only two items was identified. This particular factor was omitted because the factors which have less than three items are weak and unstable according to Costello and Osborne. ${ }^{30}$
After removing this factor, the data were analyzed again using confirmatory factor analysis to test the appropriateness of the remaining five factors. The result was a cumulative variant that could be explained by the five-factors formed, which was $54.15 \%$ with a Kaiser-Meyer-Olkin of 0.961 and sig $=0.000$. Based on this analysis result, items with a loading factor of $\geq 0.5$ were selected because items with a loading factor of $\geq 0.5$ were considered to have a significant contribution to the factor. There were seven items that had a loading factor of $<0.5$; they were "spelled out something that makes you feel offended" (loading factor 0.44 for factor 1 ), "showed unpleasant facial expressions in front of you" (loading factor 0.45 for factor 1 ), "showed your mistakes in public" (loading factor 0.49 for factor 1 ), "compared you with others" (loading factor 0.46 for factor 2), "prohibited you from doing something while he/she broke it him/herself" (loading factor 0.47 for factor 4 ), "treated you differently on the basis of gender" (loading factor 0.422 for factor 1 ), and "made decisions which were harmful to you based on unconfirmed information" (loading factor 0.49 for factor 2 ). Of the seven items, it was decided to retain one factor and eliminate six items. The item "prohibited you from doing something while he/she broke it him/herself" was retained as this particular item was able to improve the reliability of Factor 4 . The final result of this analysis was a set of 28 items valid to measure workplace incivility based on the five factors formed, as shown in Table 2.

Cronbach's alpha values of reliability for the five subscales and the total scale are shown in Table 3. All Cronbach's alpha values $\geq 0.80$, except for the Privacy Violation subscale (0.72). The Cronbach's alpha value for total scale was as high as 0.94 . This meant that there was a high internal consistency both in the subscales and in the total scale.

The intercorrelations between the subscales and the total scale are shown in Table 4. Each subscale highly correlated with the total scale (ranging from 0.70 to 0.90 ) with a significance of 0.01 . This indicates that the subscales proved to be important factors for the total scale. Meanwhile, the intercorrelations between the subscales were at moderate levels (ranging from 0.48 to 0.70 ). This means that the subscales measured aspects that were different from each other, or provided unique information in the same context. Despite its lowest correlation with the total scale, the Privacy Violation subscale correlated with other subscales at moderate levels (ranging from 0.48 to 0.54 ), slightly lower than the intercorrelations between the other subscales. 
Table 2 Confirmatory factor analysis pattern matrix loadings $(\mathrm{N}=56 \mathrm{I})$

\begin{tabular}{|c|c|c|c|c|c|}
\hline \multirow[t]{2}{*}{ Items } & \multicolumn{5}{|c|}{ Factor loading } \\
\hline & $\mathbf{I}$ & 2 & 3 & 4 & 5 \\
\hline \multicolumn{6}{|l|}{ Factor I: personal affairs' intervention } \\
\hline Gossiped behind your back & 0.77 & 0.20 & 0.20 & 0.12 & 0.16 \\
\hline Talked about you behind your back & 0.75 & 0.13 & 0.27 & 0.18 & 0.09 \\
\hline Secretly tried to know what you are doing & 0.62 & 0.31 & 0.11 & 0.18 & 0.19 \\
\hline Publicly discussed your confidential personal information & 0.58 & 0.11 & 0.14 & 0.25 & 0.20 \\
\hline Intervened in your personal affairs & 0.57 & 0.17 & 0.19 & 0.16 & 0.27 \\
\hline Brought up your past problems & 0.55 & 0.26 & 0.35 & 0.22 & 0.13 \\
\hline \multicolumn{6}{|l|}{ Factor 2: abandonment } \\
\hline $\begin{array}{l}\text { Was excessively slow in returning your electronic messages or emails without good reason for } \\
\text { the delay }\end{array}$ & 0.03 & 0.67 & 0.09 & 0.07 & 0.25 \\
\hline Ignored opinions you offered in the meeting forum & 0.23 & 0.64 & 0.21 & 0.18 & 0.15 \\
\hline Avoided consulting you when they would normally be expected to do so & 0.42 & 0.57 & 0.04 & -0.02 & 0.10 \\
\hline Responded to your questions in short and unfriendly ways & 0.39 & 0.54 & 0.29 & 0.11 & 0.11 \\
\hline Did not consult you in reference to a decision you should have been involved in & 0.06 & 0.53 & 0.22 & 0.41 & 0.04 \\
\hline Broke his/her promise to you without feeling guilty & 0.34 & 0.53 & 0.15 & 0.38 & 0.09 \\
\hline Intentionally failed to pass on information which you should have been made aware of & 0.31 & 0.52 & 0.15 & 0.29 & 0.10 \\
\hline Showed anger by way of ignoring you & 0.42 & 0.52 & 0.19 & 0.11 & 0.17 \\
\hline \multicolumn{6}{|l|}{ Factor 3: unfriendly communication } \\
\hline Spoke rudely to you in public & 0.29 & 0.23 & 0.70 & 0.05 & 0.16 \\
\hline Raised their voice while speaking to you & 0.07 & 0.15 & 0.66 & 0.23 & 0.07 \\
\hline Used an inappropriate tone when speaking to you & 0.24 & 0.01 & 0.64 & 0.10 & 0.29 \\
\hline Reprimanded you in front of unconcerned others & 0.26 & 0.32 & 0.60 & 0.07 & 0.13 \\
\hline Made cynical remarks about you & 0.49 & 0.21 & 0.52 & 0.21 & 0.08 \\
\hline \multicolumn{6}{|l|}{ Factor 4: inconsiderate behavior } \\
\hline Gave you orders which are unrelated to job & 0.27 & 0.20 & 0.19 & 0.64 & 0.15 \\
\hline Claimed your work as his/hers & 0.31 & 0.22 & 0.05 & 0.57 & 0.05 \\
\hline Asked you to do some work without considering your condition & 0.19 & 0.42 & 0.36 & 0.51 & 0.17 \\
\hline Prohibited you to do something while he/she broke it & 0.37 & 0.43 & 0.24 & 0.47 & 0.14 \\
\hline \multicolumn{6}{|l|}{ Factor 5: privacy invasion } \\
\hline Took items from your desk without prior permission & 0.09 & 0.08 & 0.12 & 0.49 & 0.64 \\
\hline Opened your desk drawers without prior permission & 0.15 & 0.14 & 0.16 & 0.21 & 0.60 \\
\hline Read communications addressed to you, such as emails, faxes, or SMS without prior permission & 0.32 & 0.15 & -0.04 & -0.18 & 0.58 \\
\hline Took stationery from your desk without later returning it & 0.04 & -0.01 & 0.11 & 0.54 & 0.57 \\
\hline Turned on the music loud so that it interfered with your work & 0.20 & 0.25 & 0.19 & 0.06 & 0.54 \\
\hline
\end{tabular}

Notes: Extraction method: principal component analysis. Rotation method: varimax with Kaiser normalization. Rotation converged in 25 iterations. Values in bold show that the value is the highest loading factor compared to other values.

Abbreviation: SMS, short message service.

Table 3 Incivil behavior scale reliability

\begin{tabular}{lll}
\hline Construct & Number of items & $\alpha$ Reliability \\
\hline Personal affairs' intervention & 6 & 0.86 \\
Abandonment & 8 & 0.85 \\
Unfriendly communication & 5 & 0.80 \\
Inconsiderate behavior & 4 & 0.80 \\
Privacy invasion & 5 & 0.72 \\
Total scale & 28 & 0.94 \\
\hline
\end{tabular}

Note: $\mathrm{N}=561$.

\section{Discussion}

This study suggested that uncivil behaviors in Indonesia turned out to be similar to uncivil behaviors in other countries as outlined in the items of the WIS developed in the present study, although they have some distinctive forms as well.
Table 4 Intercorrelations between subscales and total scale

\begin{tabular}{|c|c|c|c|c|c|c|}
\hline Construct & $\mathbf{I}$ & 2 & 3 & 4 & 5 & 6 \\
\hline $\begin{array}{l}\text { I. Personal affairs' } \\
\text { intervention }\end{array}$ & - & $0.70 * *$ & $0.67 * *$ & $0.63 * *$ & $0.52^{* *}$ & $0.87^{* *}$ \\
\hline 2. Abandonment & & - & $0.65 * *$ & $0.70 * *$ & $0.5 I^{* *}$ & $0.90 * *$ \\
\hline 3. Unfriendly communication & & & - & $0.6 I^{* *}$ & $0.48 * *$ & $0.8 I^{* *}$ \\
\hline 4. Inconsiderate acts & & & & - & $0.54 * *$ & $0.84 * *$ \\
\hline 5. Privacy invasion & & & & & - & $0.70^{* *}$ \\
\hline 6. Total scale & & & & & & - \\
\hline
\end{tabular}

Note: $\mathrm{N}=561 ; * * p<0.01$.

Martin and Hine ${ }^{22}$ were the only researchers who developed the UWBQ with a multidimensional approach. When compared with the factors they found, there were both similarities and differences in the factors resulting from the present study. In general, the behaviors contained in the items of UWBQ 
were also found in Indonesia and they became items on the scale developed in the present study. There was at least one factor that contained relatively the same items, so it was given the same name, privacy invasion. The comparison of items between the two full scales is shown in Table 5 .
The results of this study provide support for Martin and Hine's ${ }^{22}$ suggestion that it is necessary to view workplace uncivil behavior as a multidimensional rather than unidimensional construct as Cortina et $\mathrm{al}^{7}$ suggested. The use of more comprehensive items has proved to result in a measure of

Table 5 Comparisons of IWIS', UWBQ's, and WIS' items

\begin{tabular}{ll}
\hline IWIS & UWBQ item (Factor) \\
\hline $\begin{array}{ll}\text { Factor I: personal affairs' intervention } \\
\text { Gossiped behind your back }\end{array}$ & Gossiped behind your back (Factor 4: gossiping) \\
Talked about you behind your back & Talked about you behind your back (Factor 4: gossiping) \\
Secretly tried to know what you are doing & - \\
Publicly discussed your confidential personal & Publicly discussed your confidential personal information \\
information & (Factor 4: gossiping) \\
Intervened in your personal affairs & - \\
Brought up your past problems & -
\end{tabular}

Factor 2: abandonment

Was excessively slow in returning your electronic messages or emails without a good reason for the delay Ignored the opinions you offered at the meeting forum

Avoided consulting you when they would normally be expected to do so

Responded to your questions in a short and unfriendly way

Did not consult you in reference to a

decision you should have been involved in

Broke promise to you without feeling guilty

Intentionally failed to pass on information which you should have been made aware of

Showed anger by way of ignoring you

Factor 3: unfriendly communication

Spoke rudely to you in public

Raised their voice while speaking to you

Used an inappropriate tone when speaking

to you

Reprimanded you in front of unconcerned

others

Made cynical remarks about you
Was excessively slow in returning your phone messages or emails without a good reason for the delay (Factor 3: exclusionary behavior) $-$

Avoided consulting you when they would normally be expected to do so (Factor 3: exclusionary behavior)

Did not consult you in reference to a decision you should have been involved in (Factor 3: exclusionary behavior)

Gave unreasonably short notice when canceling or scheduling events you were required to be present for (Factor 3: exclusionary behavior) Intentionally failed to pass on information which you should have been made aware of (Factor 3: exclusionary behavior)

Failed to inform you of a meeting you should have been informed about (Factor 3: exclusionary behavior)

Were unreasonably slow in seeing to matters on which you were reliant on them for, without good reason (Factor 3: exclusionary behavior)

Raised their voice while speaking to you (Factor I: hostility)

Used an inappropriate tone when speaking to you

(Factor I: hostility) $-$

Made snide remarks about you (Factor 4: gossiping)

WIS 7 item $^{*}$ and 10 item $^{* *}$

-
-
-
-
-

Made unwanted attempts to draw you into a discussion of personal matters*

$-$

Paid little attention to your statement or showed little interest in your opinion*

$-$

Ignored you or failed to speak to you (eg, gave you "the silent treatment")

Ignored or excluded you from professional camaraderie* Doubted your judgment on a matter over which you have responsibility*

Made jokes at your expense ${ }^{* *}$

Interrupted or "spoke over" you Yelled, shouted, or swore at you**

Made insulting or disrespectful remarks about you ${ }^{\text {** }}$

$-$

Made demeaning or derogatory remarks about you*

(Continued) 


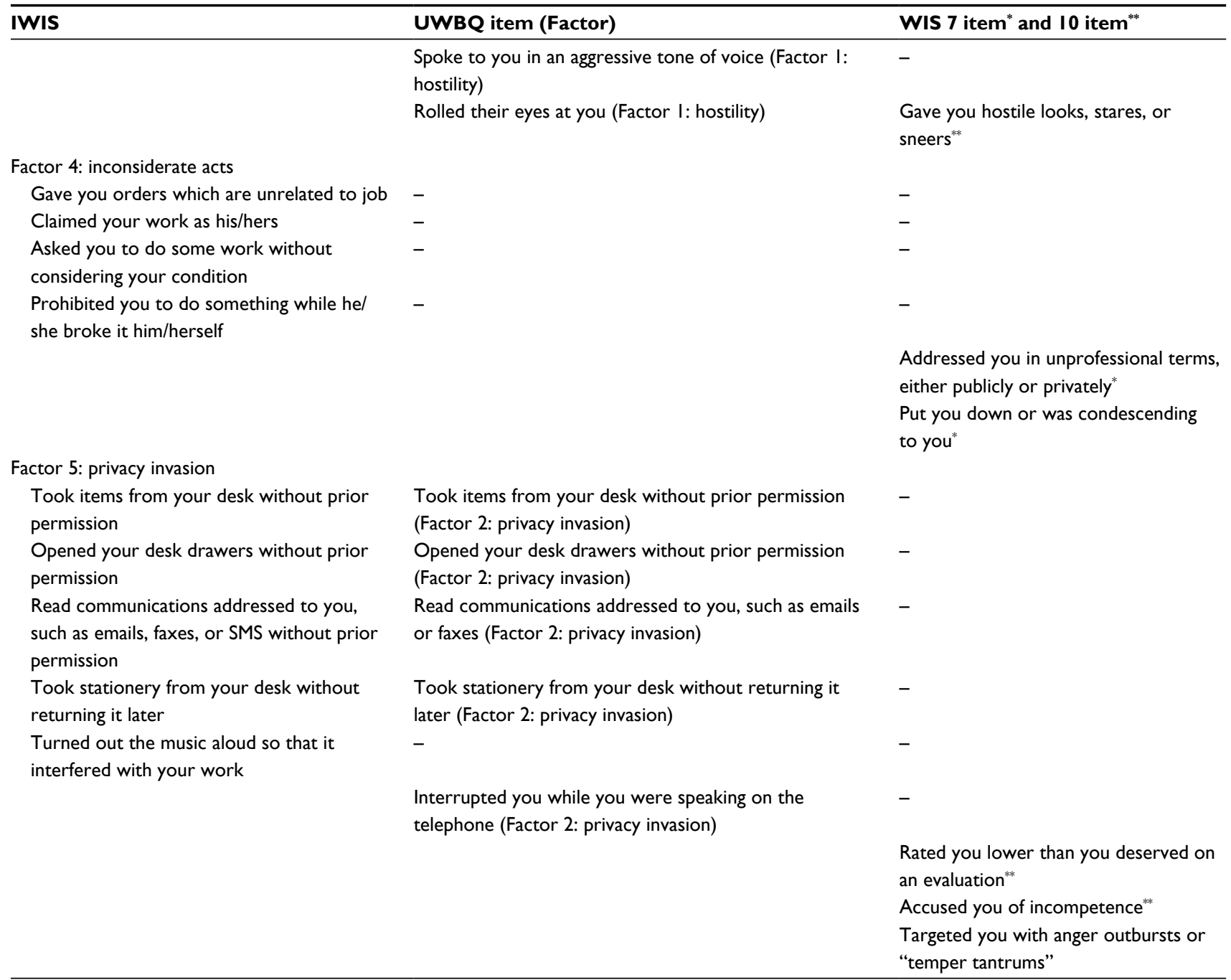

Note: *WIS 7 item; **10 item.

Abbreviations: IWIS, Indonesian Workplace Incivility Scale; SMS, short message service; UWBQ, Uncivil Workplace Behavior Questionnaire; WIS, Workplace Incivility Scale.

uncivil behavior with more complex structures. While Martin and Hine ${ }^{22}$ found four factors, the present study found five factors. Four of the five factors identified in the present study were almost identical to those found by Martin and Hine, while the fifth factor, inconsiderate behavior, was a typical behavior found in this study. Inconsiderate behavior is an arbitrary behavior derived from the superior function without regards to the rights and conditions of the subordinates. Inconsiderate behaviors found in the present study may be committed either by superiors or co-workers. Of the practical benefits of using a multidimensional construct-based incivility scale was that it allowed identification of specific incivility in question.

WIS developed in this study had Cronbach's alpha of $>0.80$, except for privacy violation. Even the Cronbach's alpha of total Indonesian WIS (alpha 0.94, 28 items) was higher than that of UWBQ (alpha 0.92, 17 items) and WIS (alpha 84, 7 items). The difference in Cronbach's alpha coefficients was probably due to the difference in the number of items. Martin and Hine ${ }^{22}$ stated that when the number of WIS items is added by 10, it is predicted that the Cronbach's alpha coefficient would be as high as 0.93 , assuming the average correlation between items remains constant. This means the internal consistency of Indonesian WIS is relatively similar to that of UWBQ and WIS. Thus, researchers have options of scales that measure various workplace Incivility with comparable qualities.

Further validation by testing the convergent validity using other valid WISs such as WIS and UWBQ and the discriminant validity using aggression or other forms of mistreatment 
behaviors criteria and other types of validations need to be done at the next stage to further test the quality of the scales that have been obtained.

\section{Limitations and recommendations}

Research on incivility behavior associated with local/cultural factors is important to be conducted. This research has put in the context of Indonesian culture and it is also necessary to conduct similar study in other countries with different cultures. The knowledge of incivility behavior based on its own culture will provide more appropriate and useful information for the management to take preventive actions as well as interventions to reduce uncivil behaviors in the workplace. Furthermore, the organization will benefit from a work environment that has a culture of respect that is free of incivility, bullying, and violence in the workplace.

However, this study has some limitations because it examines incivility behavior in the context of general culture. Further research is necessary to examine the specific cultural factors of Indonesia, such as gender bias, power imbalance, politeness, and so forth. The participants in this research who were asked for the incivility behaviors they had experienced in the past year may have an information bias by the factors of forgetfulness. Further research may require a shorter time, that is, 3 or 6 months.

\section{Disclosure}

The authors report no conflicts of interest in this work.

\section{References}

1. Pearson CM, Andersson LM, Porath CL. Assessing and attacking workplace incivility. Organ Dyn. 2000;29(2):123-137.

2. Porath C, Pearson C. The price of incivility. Harv Bus Rev. 2013; 91(1-2):115-121.

3. Pearson CM, Porath CL. The Cost of Bad Behavior: How Incivility is Damaging Your Business and What to Do About It. New York, NY, USA: Penguin; 2009.

4. Pearson CM, Porath CL. On the nature, consequences and remedies of workplace incivility: no time for "nice"? Think again. Acad Manag Exec. 2005;19(1):7-18.

5. Lim S, Cortina LM, Magley VJ. Personal and workgroup incivility: Impact on work and health outcomes. JAppl Psychol. 2008;93(1):95-107.

6. Porath CL, Gerbasi A, Schorch SL. The effects of civility on advice, leadership, and performance. J Appl Psychol. 2015;100(5):1527-1541.

7. Cortina LM, Magley VJ, Williams JH, Langhout RD. Incivility in the workplace: incidence and impact. J Occup Health Psychol. 2001;6(1):64-80.
8. Andersson LM, Pearson CM. Tit for tat? The spiraling effect of incivility in the workplace. Acad Manag Rev. 1999;24(3):452-471.

9. Lim S, Cortina LM. Interpersonal mistreatment in the workplace: the interface and impact of general incivility and sexual harassment. J Appl Psychol. 2005;90(3):483-496.

10. Einarsen, S. The nature and causes of bullying at work. Int J Manpow. 1999;10:16-27.

11. Einarsen S, Skogstad A. Bullying at work: epidemiological findings in public and private organizations. Eur J Work Organ Psychol. 1996;5:185-201.

12. Tepper BJ. Consequences of abusive supervision. Acad Manag J. 2000;43(2):178-190.

13. Hershcovis MS. "Incivility, social undermining, bullying...oh my!": a call to reconcile constructs within workplace aggression research. $J$ Organ Behav. 2011;32(3):499-519.

14. Griffin B. Multilevel relationships between organizational-level incivility, justice and intention to stay. Work Stress. 2010;24(4):309-323.

15. Yeung A, Griffin B. Workplace incivility: does it matter in Asia. People Strategy. 2008;31(3):14-19.

16. Tsuno K, Kawakami N, Shimazu, A, Shimada K. Inoue, A, Leiter MP. Workplace incivility in Japan: reliability and validity of the Japanese version of the modified Work Incivility Scale. J Occup Health. 2017;59(3):237-246.

17. Ghosh R. Workplace incivility in Asia: how do we take a socio-cultural perspective? Hum Res Dev Int. 201720(4):263-267.

18. Kane K, Montgomery K. A framework for understanding disempowerment in organizations. Hum Res Manag. 1998;37(4):263-275.

19. Montgomery K, Kane K, Vance CM. Accounting for differences in norms of respect: a study of assessments of incivility through the lenses of race and gender. Group Organ Manag. 2004;29(2):248-268.

20. Schilpzand P, De Pater IE, Erez A. Workplace incivility: a review of the literature and agenda for future research. J Organ Behav. 2016;37(S1):S57-S88.

21. Cortina LM, Kabat-Farr D, Leskinen EA, Huerta M, Magley VJ. Selective incivility as modern discrimination in organizations evidence and impact. J Manag. 2013;39:1579-1605.

22. Martin RJ, Hine DW. Development and validation of the uncivil workplace behavior questionnaire. J Occup Health Psychol. 2005;10(4): 477-490.

23. Burnfield JL, Clark OL, Devendorf SA, Jex SM. Understanding workplace incivility: Scale development and validation. Poster presented at: 19th Annual Meeting of the Society for Industrial and Organizational Psychology; April 2-4, 2004; Chicago, USA.

24. Guidroz AM, Burnfield-Geimer JL, Clark O, Schwetschenau HM, Jex SM. The Nursing Incivility Scale: development and validation of an occupation-specific measure. J Nurs Meas. 2010;18(3):176-200.

25. Wilson NL, Holmvall CM. The development and validation of the incivility from customers scale. JOccup Health Psychol. 2013;18(3):310-326.

26. Lim S, Lee A. Work and nonwork outcomes of workplace incivility: does family support help? J Occup Health Psychol. 2011;16(1):95-111.

27. Boyatzis RE. Transforming Qualitative Information: Thematic Analysis and Code Development. London: Sage Publication; 1998.

28. Rosenthal R, Rosnow RL. Essentials of Behavioral Research: Methods and Data Analysis. 2nd ed. New York, NY, USA: McGraw Hill; 1991.

29. Cattel RB. The Scientific Use of Factor Analysis in Behavioral and Life Sciences. New York, NY, USA: Plenum Press; 1978.

30. Costello AB, Osborne JW. Best practices in exploratory factor analysis: four recommendations for getting the most from your analysis to the practical assessment. Res Eval. 2005;10(7):1-9. 


\section{Publish your work in this journal}

Psychology Research and Behavior Management is an international, peerreviewed, open access journal focusing on the science of psychology and its application in behavior management to develop improved outcomes in the clinical, educational, sports and business arenas. Specific topics covered in the journal include: Neuroscience, memory and decision making; Behavior modification and management; Clinical applications; Business and sports performance management; Social and developmental studies; Animal studies. The manuscript management system is completely online and includes a very quick and fair peer-review system, which is all easy to use. Visit http://www dovepress.com/testimonials.php to read real quotes from published authors.

Submit your manuscript here: https://www.dovepress.com/psychology-research-and-behavior-management-journal 